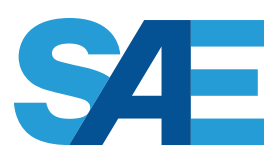

INTERNATIONAL。

\title{
Effect of Spark Timing on Performance and Emissions of a Small Spark Ignition Engine with Dual Ethanol Fuel Injection
}

Nizar F.O. Al-Muhsen and Guang Hong

University of Technology Sydney

CITATION: Al-Muhsen, N. and Hong, G., "Effect of Spark Timing on Performance and Emissions of a Small Spark Ignition Engine with Dual Ethanol Fuel Injection," SAE Technical Paper 2017-01-2230, 2017, doi:10.4271/2017-01-2230.

Copyright (C) 2017 SAE International

\begin{abstract}
Ethanol as a renewable fuel has been used widely in vehicles. Dual fuel injection is one of the new techniques in development for increasing the engine's thermal efficiency and reducing the pollutant emissions. This study reports experimental investigation to the dual ethanol fuel injection with a focus on the effect of spark timing on the engine performance at different volumetric ratios of ethanol directly injected to ethanol port injected. Experiments were conducted on a single cylinder $250 \mathrm{cc}$ spark ignition engine at two engine loads and 3500 RPM. The spark timing was varied from 15 to 42 CAD bTDC at the light load and from 15 to 32 CAD bTDC at the medium load, while the volumetric ratio of direct injection (DI\%) was varied from $0 \%$ to $100 \%$. Experimental results showed that DI $100 \%$, the best indicated mean effective pressure (IMEP) and thermal efficiency occurred at around $30 \mathrm{CAD}$ bTDC at the light load and $23 \mathrm{CAD}$ bTDC at the medium load, which were the minimum spark advance for the best torque (MBT). At MBT spark timing, the IMEP at DI56\% and light engine load was $8.28 \%$ greater than that at 15 CAD bTDC which was the original spark timing set by the manufacturer, and the combustion duration (CA10-90\%) was $41.8 \%$ shorter. These results were attributed to the improved combustion phase associated with the increased combustion pressure and temperature when the spark timing was advanced. However, the indicated specific hydrocarbon and carbon monoxide emissions increased with advanced spark timing and increased DI ratio. These could be caused by local rich mixture formed by fuel impinged to the chamber walls and the ethanol's cooling effect associated with the direct injection. On the other hand, because of the charge cooling effect of DI, the indicated specific nitric oxide emission decreased with increased DI ratio. At MBT timing and light load, the indicated specific nitric oxide emission decreased by $37.53 \%$ at DI56\% and $67.39 \%$ at DI $100 \%$ compared to port injection only.
\end{abstract}

\section{Introduction}

The automobiles have become one of the biggest sources of pollutions to the atmosphere. Pollutants generated by automobiles have caused serious health problems and aggravate the global warming. It was reported that the transportation was responsible for about 25 percent of the produced greenhouse gas emissions [1] . In order to reduce the automobile pollutant emissions, more and more stringent regulations have been enforced [2]. This has driven the manufacturers and researchers to develop new technologies to improve the engine performance. Ethanol fuel has become one of the most common biofuels for internal combustion (IC) engines as an enhancer and/or alternative to the fossil fuels [ $\underline{3}]$. Ethanol has stronger anti-knock ability due to its greater octane number, latent heat of vaporisation and auto-ignition temperature compared to gasoline as shown in Table 1. New technologies have been in development to exploit the benefits of ethanol fuel to the IC engines applications.

Extensive research has been conducted to investigate the effect of blended ethanol and gasoline fuels on the conventional SI engines. Bielaczyc et al. [4] tested an SI engine under a wide range of ethanol-gasoline blended fuel ratios from $5 \%$ to $85 \%$. Their results showed that blended ethanol and gasoline fuels had a significant effect on the engine performance and emissions. The combustion was improved by combustion speed increased by and the oxygen component of the ethanol fuel. The higher out-ignition temperature of ethanol combined with a great latent heat of vaporisation mitigated the engine knock. Ramadhas et al. []ㅡ investigated the combustion and emissions characteristics of the ethanol-gasoline blends with 5\% to $20 \%$ ethanol fuel, using a multipoint port fuel injection (MPFI) system on a small car engine. Compared to gasoline fuel, it was concluded that using the MPFI system to the ethanol-gasoline blended fuel could improve the combustion quality and reduce the exhaust gas emissions. Masum B. et al. reviewed the feasibility of 
burning ethanol fuel in SI engines [6]. Their results showed that the combustion efficiency was improved due to the ethanol's oxygen content and high laminar flame speed. Moreover, because of ethanol's greater octane number and latent heat of vaporisation, a higher compression ratio and more advanced level of turbocharged engines could be potentially achieved $[\underline{7}, \underline{8}]$. Additionally, the cooling effect of the ethanol fuel could be further enhanced if it is injected directly into the cylinder [9]. This might reduce the combustion temperature and thus the indicated specific nitric oxide emission (ISNOx).

Dual fuel combustion has been investigated in recent years to exploit the potential applications of ethanol to spark ignition (SI) engines [10, $\underline{11}, \underline{12}, \underline{13}, \underline{14}, \underline{15}]$. Kasseris E. and Heywood J. [도, $\underline{16}]$ developed a methodology to evaluate quantitatively the effect of ethanol's charge cooling and auto-ignition resistance on the engine knock limit when direct injection of blended gasoline and ethanol fuels were applied. Higher ethanol percentages were commonly used in Brazil and United States aiming to reduce the depletion of hydrocarbon fuel and improve the engine performance $[\underline{17}, \underline{18}]$. The effect of E85 on the engine performance, combustion and emission characteristics was investigated $[\underline{19}, \underline{20}, \underline{21}, \underline{22}]$. Ethanol direct injection plus gasoline port injection (EDI+GPI) has been in development in recent years [13]. Experimental investigation showed that the EDI+GPI strategy improved the engine thermal efficiency and reduced the ISNOx emission in a certain range of ratios of two fuels $[\underline{13}, \underline{23}]$. However, the indicated specific hydrocarbon (ISHC) increased significantly. It was reported that port injection of ethanol fuel could improve the combustion quality and subsequently the engine thermal efficiency in a naturally aspirate SI engine $[\underline{18}, \underline{24}]$. This improvement could be attributed to the greater combustion speed associated with oxygen component of ethanol. On the other hand, a significant reduction in the IMEP and thermal efficiency was reported at 100\% ethanol direct injection [9]. This could be due to the high ethanol impingement and the over cooling effect of EDI. Moreover, the measured emissions like the indicated specific carbon monoxide (ISCO) and ISHC were increased due to the poor mixture quality. This could be associated with the slow evaporation speed of ethanol fuel at low ambient temperature [25]. However, the ISNOx emission decreased considerably due to the direct ethanol injection. Ethanol fuel has been widely used in Brazil (neat ethanol) and U.S. (E85) as an alternative fuel. To understand the dual fuel system applied to engines burning ethanol fuel only, experiments were conducted to investigate the engine performance with direct (DI) and port injection (PI) of ethanol fuel [26]. Their results showed that the dual ethanol injection strategy (DualEI) could significantly improve the combustion performance and reduce the emissions compared to gasoline only.

Engine spark timing is one of the important parameters to maximise the engine power and minimise the emissions [27]. Advancing the spark timing can hinder the moving piston due to the early combustion and results in the reduced network; retarding the spark timing can reduce the combustion pressure and temperature [28] Therefore, the MBT timing needs to be determined to maximise the engine torque without knocking. The presented study reports an experimental investigation of the effect of the spark timing on the combustion and emissions characteristics to the SI engine equipped with a DualEI system. This includes the identification of the MBT timing and the trade-off between the engine power and the emissions.
Table 1. Comparison between gasoline and ethanol fuel properties.

\begin{tabular}{|l|l|l|}
\hline \multicolumn{1}{|c|}{ Property } & \multicolumn{1}{c|}{ Gasoline } & \multicolumn{1}{c|}{ Ethanol } \\
\hline Chemical formula (-) & $\mathrm{C}_{2}-\mathrm{C}_{12}[6]$ & $\mathrm{C}_{2} \mathrm{H}_{5} \mathrm{OH}[6]$ \\
\hline Viscosity $(\mathrm{kg} / \mathrm{m} . \mathrm{s})$ & $0.0004549[29]$ & $0.001007[29]$ \\
\hline $\mathrm{H} / \mathrm{C}($ Atom ratio) & $1.795[6]$ & $3[6]$ \\
\hline O/C (Atom ratio) & $0[6]$ & $0.5[6]$ \\
\hline Stoichiometric air/fuel ratio & $14.8: 1[13]$ & $9.0: 1[13]$ \\
\hline Research octane number $(-)$ & 91 & $106[13]$ \\
\hline Lower heating value $(\mathrm{MJ} / \mathrm{kg})$ & $42.9[13]$ & $26.9[13]$ \\
\hline $\begin{array}{l}\text { Laminar flame speed } @ 100 \mathrm{kPa}, \\
100^{\circ} \mathrm{C}, \lambda=1(\mathrm{~m} / \mathrm{s})\end{array}$ & $\sim 0.49[30]$ & $\sim 0.62[30]$ \\
\hline Latent heat of vaporization $(\mathrm{kJ} / \mathrm{kg})$ & $380-400[6]$ & $900-920[6]$ \\
\hline Saturation vapor pressure $(\mathrm{kPa})$ & $28.828[29]$ & $8.773[29]$ \\
\hline Auto ignition temperature $\left({ }^{\circ} \mathrm{C}\right)$ & $257[6]$ & $425[6]$ \\
\hline
\end{tabular}

Table 2. Engine specifications.

\begin{tabular}{|l|l|}
\hline Engine Type & Single Cylinder, 4-stroke, SOHC \\
\hline Displacement & $249.0 \mathrm{cc}$ \\
\hline Bore & $74.0 \mathrm{~mm}$ \\
\hline Stroke & $58.0 \mathrm{~mm}$ \\
\hline Compression Ratio & $9.8: 1$ \\
\hline Intake Valve Open (IVO) & $22.20 \mathrm{CAD}$ bTDC (Intake TDC) \\
\hline Intake Valve Close (IVC) & $53.80 \mathrm{CAD}$ aBDC (Compression BDC) \\
\hline Exhaust Valve Open (EVO) & $54.60 \mathrm{CAD}$ bBDC (Power BDC) \\
\hline Exhaust Valve Close (EVC) & $19.30 \mathrm{CAD}$ aTDC (Intake TDC) \\
\hline
\end{tabular}

\section{Experimental Setup and Methodology}

\section{Engine Test Rig}

Figure 1 shows the schematic diagram of the research engine. A modified Yamaha YBR250 motorcycle engine was used in the experiments. It is a single cylinder four-stroke air-cooled naturally aspirated spark ignition engine. The engine was originally equipped with a gasoline port injection system. Table 2 shows the specifications of the YBR250 engine. The original engine was modified by Hents Technology to meet the research needs. The engine modification included the installation of a direct fuel injection system and an electronic control unit (ECU) which was used to adjust the throttle position, the spark timing, the direct injection timing, the quantity of the injected fuel per cycle and the direct injection pressure. The direct fuel injection system comprised of a returnless high-pressure pump and a six-hole high-pressure injector [31]. The injector was side installed between the intake valve seat and the spark plug [13]. The slope angles of the injector are $15^{\circ}$ from the horizontal surface of the cylinder head to the axis of the injector and $12^{\circ}$ from the vertical surface of the cylinder head. Table 3 shows the major specifications of the direct fuel injector. More details about the nozzle plume bend angles and their distribution can be found in [르. The injection pulse width was used to calibrate and measure the ethanol fuel flow rate. An eddy current dynamometer was used to set the required engine speed and measure the real-time engine torque. A Kistler 6115B spark plug cylinder pressure transducer and a Kistler 5011 charge amplifier were used to record the in-cylinder pressure. K-type thermocouples were used to measure the cylinder head temperature and exhaust gas 
temperature with a resolution of $0.1{ }^{\circ} \mathrm{C}$ and uncertainty of $0.35 \%$ [33]. An MEXA-584L Horiba exhaust gas analyser was used to measure the exhaust gas emissions of $\mathrm{CO}, \mathrm{CO} 2, \mathrm{HC}, \mathrm{NO}$ and lambda ( $\lambda$ ). The $\mathrm{H} / \mathrm{C}$ and $\mathrm{O} / \mathrm{C}$ ratios were set to be 3.0 and 0.5 respectively as shown in Table 1. The intake airflow was stabilised in an $80 \mathrm{~L}$ intake buffer tank. The intake airflow rate was measured using a ToCeiL20N thermal air-mass flow meter.

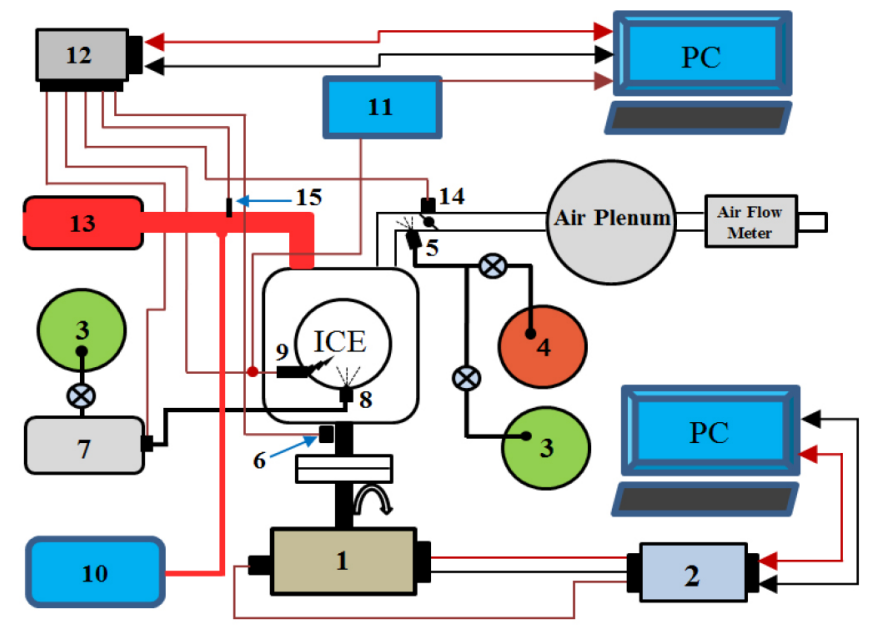

1. Eddy Current Dynamometer 2. Dynamometer Controller 3. Ethanol Fuel Tank 4. Gasoline Fuel Tank 5. Low-Pressure Injector 6. Crankshaft Encoder 7. High-Pressure Ethanol Pump 8. High-Pressure Ethanol Injector 9. Kistler 6115B Pressure Transducer 10. MEXA-584L Gas Analyser 11. Charge Amplifier 12. Electronic Control Unit 13. Exhaust Gas Catalyser 14. Throttle Position Sensor 15. Bosh Wide-band Lambda Sensor

Figure 1. Schematic diagram of the dual ethanol injection engine.

Table 3. Specifications of the direct fuel injector $[\underline{31}, \underline{33}]$

\begin{tabular}{|l|l|}
\hline Manufacturer & Bosch Engineering \\
\hline Operating pressure & Up to $500 \mathrm{bar}$ \\
\hline Number of holes & 6 holes \\
\hline Hole diameter & $110 \mu \mathrm{m}$ \\
\hline Operating temperature range & -31 to $130^{\circ} \mathrm{C}$ \\
\hline Flow rate @ 100 bar & $\mathrm{Up}$ to $1640 \mathrm{~g} / \mathrm{min}$ \\
\hline Spray angle single beam & $17^{\circ}$ \\
\hline
\end{tabular}

\section{Experimental Methodology}

In the experiment, the engine was started and warmed up using GPI only until the cylinder head temperature became stable at around $200^{\circ} \mathrm{C}$. After the engine temperature became stable, the gasoline port injection was switched to ethanol port injection, and the mixture was kept at the stoichiometric condition. Table 4 lists the engine operating conditions for the experiments. The volumetric ratio of the ethanol direct injection to ethanol port injection was changed from DI0\% (PI only) to DI $100 \%$ (direct injection only). At each DI ratio, the spark timing was changed from 15 to 42 CAD bTDC at light engine load and from 15 to $32 \mathrm{CAD}$ bTDC at medium load. The spark timing of 15 CAD bTDC (ST15) was set as a baseline because it was the original spark timing before the engine was modified. The direct injection timing was $300 \mathrm{CAD}$ bTDC and port injection $410 \mathrm{CAD}$ bTDC, aimed to give sufficient time for fuel evaporation and mixing based on previous experimental investigation [13]. The throttle opening was $20 \%$ at light load and $33 \%$ at medium load. The equivalence ratio $(\lambda)$ was kept at around the stoichiometric condition $(\lambda=1)$, and the engine speed was around 3500 RPM. To keep the equivalence ratio consistent during the experiments, a Horiba exhaust gas analyser and Bosh Wide-band lambda sensor were used independently to verify the measured $\lambda$. Five samples of data were taken at each engine operation condition, and the average values were used in the calculations and analyses. The in-cylinder pressure data was recorded at 0.5 crank angle degree resolution with 100 consecutive cycles in each sample. The ensemble average of the cylinder pressure data was used in calculations of IMEP and the combustion analysing.

Table 4. Experimental operating conditions.

\begin{tabular}{|c|c|}
\hline Engine Loads & $\begin{array}{l}\text { Light load ( } 20 \% \text { Throttle opening) } \\
\text { Medium load ( } 33 \% \text { Throttle opening) }\end{array}$ \\
\hline Engine Speed (RPM) & 3500 \\
\hline Spark Timing (CAD bTDC) & $\begin{array}{l}\frac{\text { Light load: }}{40 \text { and } 42} 15,20,25,30,32,34,36,38, \\
\frac{\text { Medium Load: }}{28,30 \text { and } 32} 15,18,20,22,23,24,26 \text {, }\end{array}$ \\
\hline DI\% (volumetric percentage) & $\begin{array}{l}\text { Light load: DI0 (PI only), DI35, DI56, } \\
\text { DI60, DI80 and DI100 } \\
\text { Medium load: DI30, DI50, DI70, DI100 }\end{array}$ \\
\hline Port Fuel Injection Timing & 410CAD bTDC \\
\hline Direct Fuel Injection Timing & $300 \mathrm{CAD}$ bTDC \\
\hline
\end{tabular}

\section{Results and Discussion}

The experimental results will be presented and discussed as follows. The effect of spark timing on the IMEP and indicated thermal efficiency will be reported in the first subsection. The effect of spark timing on the combustion characteristics represented by $\mathrm{P}_{\max }, \Theta_{\mathrm{Pmax}}$, HRR and MBF50 at selected DI ratios will be reported in the second subsection. The third subsection will be focused on the effect of the spark timing on emissions at the light load.

\section{Effect of Spark Timing on the IMEP and Indicated Thermal Efficiency}

Figure 2 shows the effect of spark timing (ST) on the IMEP at different DI ratios. At all the DI ratios, IMEP increases with the ST advanced up to ST30. It then decreases with further advance of ST. As shown in Figure 2-a, at DI100\%, the IMEP increases from 0.404 MPa to $0.457 \mathrm{MPa}$ when the spark timing is advanced from ST15 to ST30 at light load. Likewise, at DI100\%, the IMEP increases from $0.625 \mathrm{MPa}$ to $0.672 \mathrm{MPa}$ when the spark timing is advanced from ST15 to ST23 at medium load, as shown in Figure 2-b. Results shown in Figure 2 are consistent with that any internal combustion engines. The maximum IMEP was achieved when the spark timing leads to increased pressure in the compression stroke and consequently the bulk combustion completed near the TDC and more network produced. It is made by advancing the spark timing to the point at which the MBF50 occurs certain degrees aTDC [34]. Here MBF50 is defined as the crankshaft angle degree when $50 \%$ of the fuel is burnt. Based on the results in Figure 2, ST30 is identified to be the MBT spark timing at the light load and ST23 the MBT spark timing at the medium load. It should be noted that, as shown in Figure 2, IMEP is increased by both advancing spark timing and DualEI strategy. The IMEP increased with the increased DI\% may be 
attributed to two main reasons. Firstly, the charge cooling effect due to ethanol's great latent heat of vaporisation associated with DI injection strategy might increase the fresh charge density hence allowing more air to be charged during the intake stroke [프] . Secondly, the oxygen content of ethanol fuel and the high combustion speed might help improve the combustion.

Figure 3 shows that the indicated thermal efficiency increases with the advanced spark timing until ST30 at light load and ST23 at medium load. At light load and DI80\%, the maximum increase of the indicated thermal efficiency is $10.68 \%$, when the spark timing is advanced from ST15 to ST30 as shown in Figure 3-a. Similarly, at medium load and DI70\%, the maximum improvement of the indicated thermal efficiency is $5.42 \%$, when the spark timing is advanced from ST15 to ST23 as shown in Figure 3-b. Further advancing the spark timing results in a reduction of thermal efficiency at both engine loads. The results shown in Figure 3 may be explained with three main causes. Firstly, the position of the start of combustion plays an important role in the engine performance [27, 28 $]$. A reduced combustion chamber volume at MBF50 leads to an increased combustion pressure and temperature. The increased cylinder temperature may increase the ethanol evaporation rate and thus improve the mixture and combustion quality. Secondly, further advancing to the spark timing from MBT timing decreases the thermal efficiency due to the early combustion. Moreover, the greater combustion temperature may promote the convective heat losses, which can partly explain the thermal efficiency reduction [36]. On the other hand, retarding the spark timing from MBT timing reduces the combustion pressure and temperature [7]. Consequently, the over cooling effect caused by DI may deteriorate the combustion performance, which can partially explain the reduction of engine thermal efficiency. Thirdly, an early combustion means a greater area of the cylinder wall that can lead to increase the heat loss through the cylinder wall. Furthermore, the air-fuel mixture has relatively less time to be homogeneously mixed before the combustion starts. This may result in a poor mixture and combustion quality.

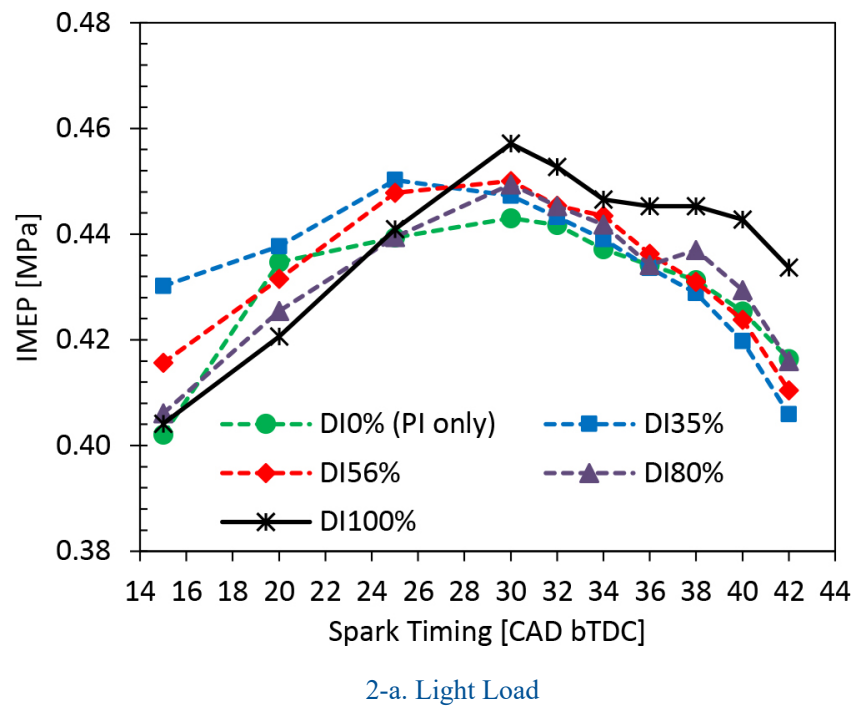

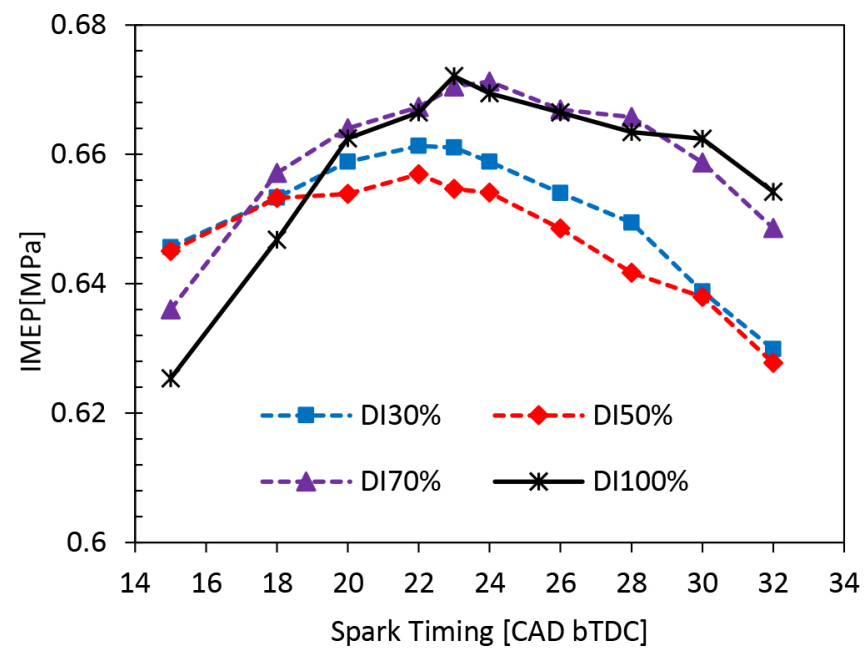

2-b. Medium Load

Figure 2. Effect of spark timing on IMEP at different DI ratios.
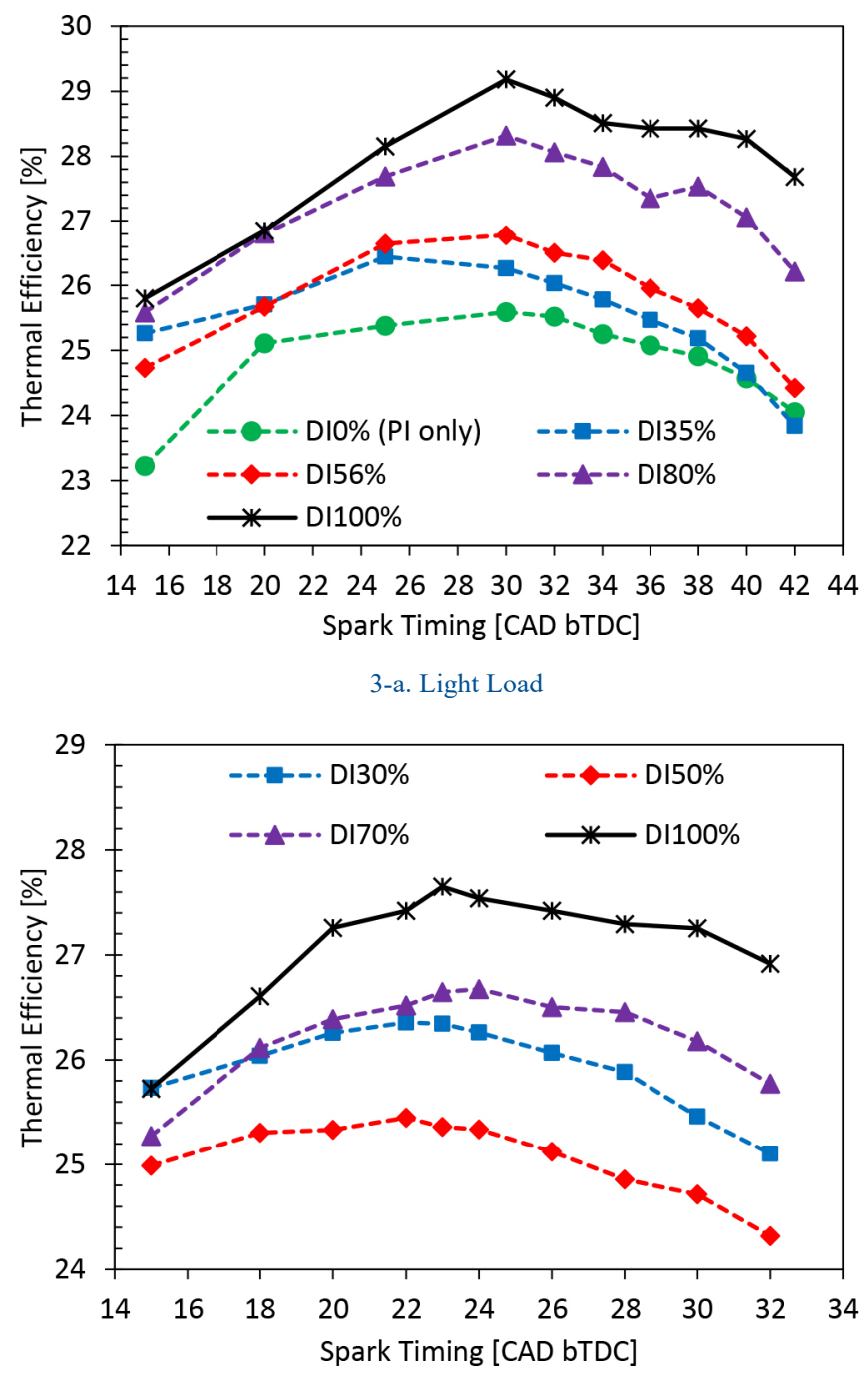

3-b. Medium Load

Figure 3. Effect of spark timing on indicated thermal efficiency at different DI ratios. 


\section{Effect of Spark Timing on Combustion Characteristics}

Combustion characteristics such as MBF50, maximum in-cylinder pressure (denoted as $\mathrm{P}_{\max }$ ) and its phase (denoted as $\Theta_{\mathrm{Pmax}}$ ), the major combustion duration (CA10-90\%) and the heat release rate (HRR) may be examined to understand the experimental results.

Figure 4 shows the effect of the spark timing on $\mathrm{P}_{\max }$ and $\Theta_{\mathrm{Pmax}_{\max }}$ at a selected DI ratio. It is well known that the engine power can be maximised when the $\mathrm{P}_{\max }$ occurs within few degrees aTDC [27]. At DI56\% and light load as shown in Figure 4-a, the $\Theta_{\text {Pmax }}$ moves by 12 degrees toward the TDC and the $\mathrm{P}_{\max }$ increases by about $1.7 \mathrm{MPa}$ with spark timing advanced from ST15 to ST42. As shown in Figure 4-b, at DI50\% and medium load, the $\Theta_{\text {Pmax }}$ moves by 13.5 degrees toward TDC and the $\mathrm{P}_{\max }$ rises by about $1.874 \mathrm{MPa}$ with spark timing advanced from ST15 to ST23. These results are consistent with the results presented in Figure 2 and Figure 3. The maximum IMEP and indicated thermal efficiency are recorded at ST30 while the $\Theta_{\text {Pmax }}$ is located at about $10 \mathrm{CAD}$ aTDC at the light load. At medium load, the maximum IMEP and the indicated thermal efficiency are recorded at ST23 while the $\Theta_{\text {Pmax }}$ is located at around 12 CAD aTDC.

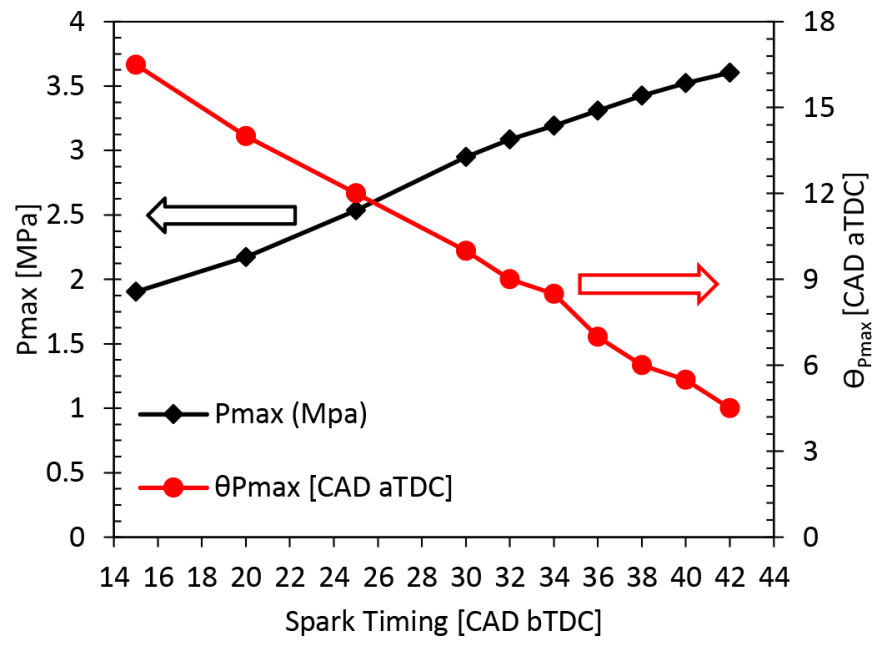

4-a. Light Load

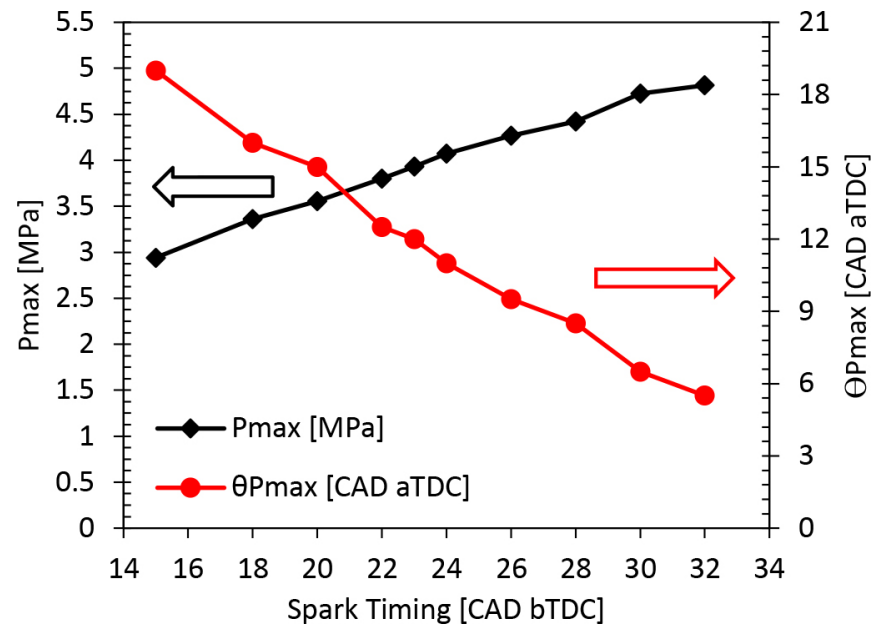

4-b. Medium Load

Figure 4. Effect of spark timing on the maximum pressure and its phase with DI56\% at light load and DI50\% at medium load.

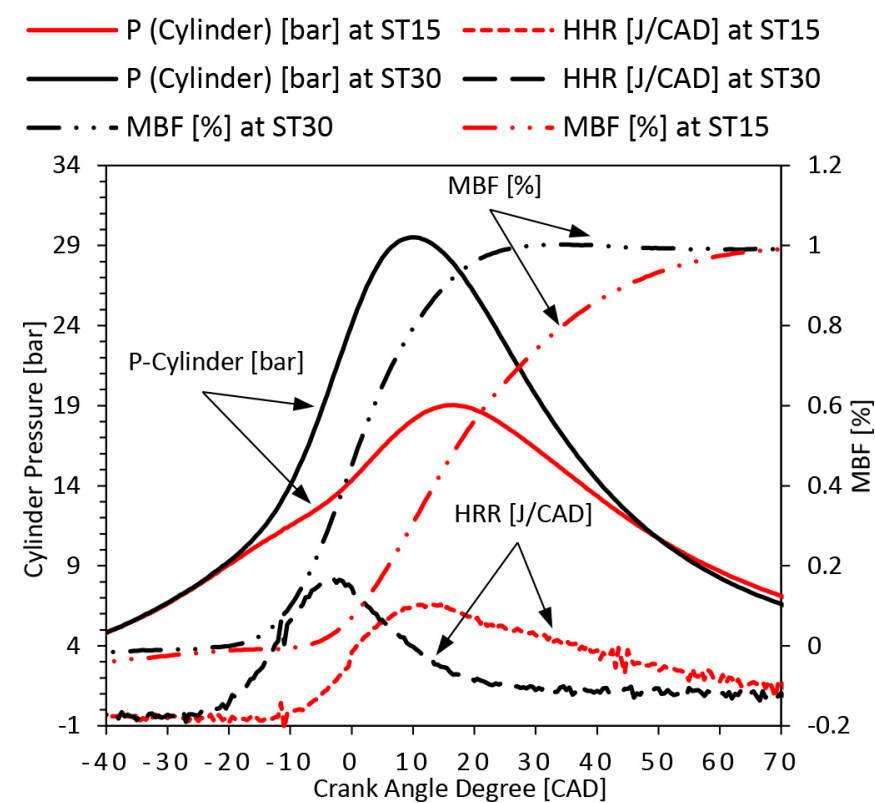

Figure 5. Cylinder pressure, MBF and HRR at ST30, DI56\% and light load.

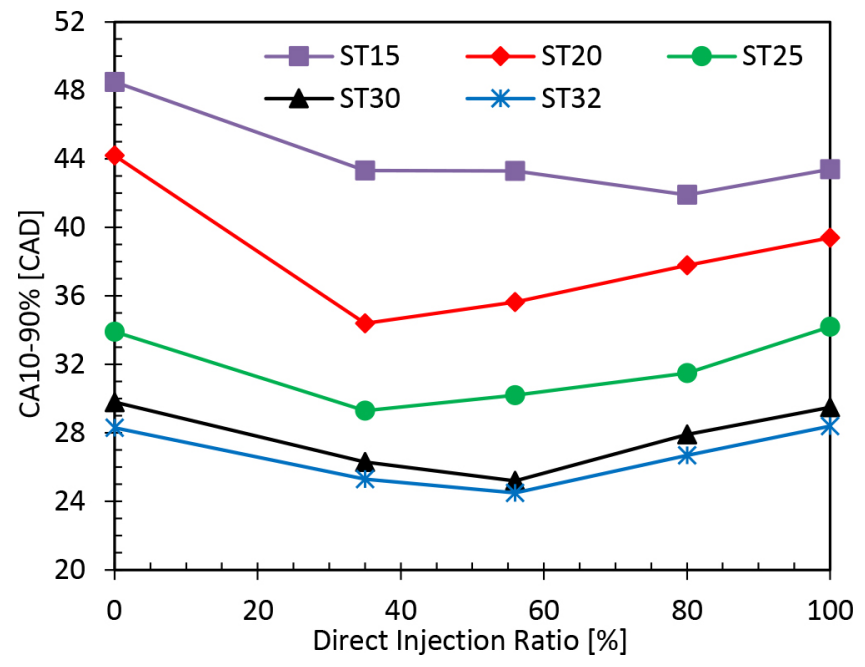

Figure 6. Variation of the major combustion duration (CA10-90\%) with DI ratio at light load.

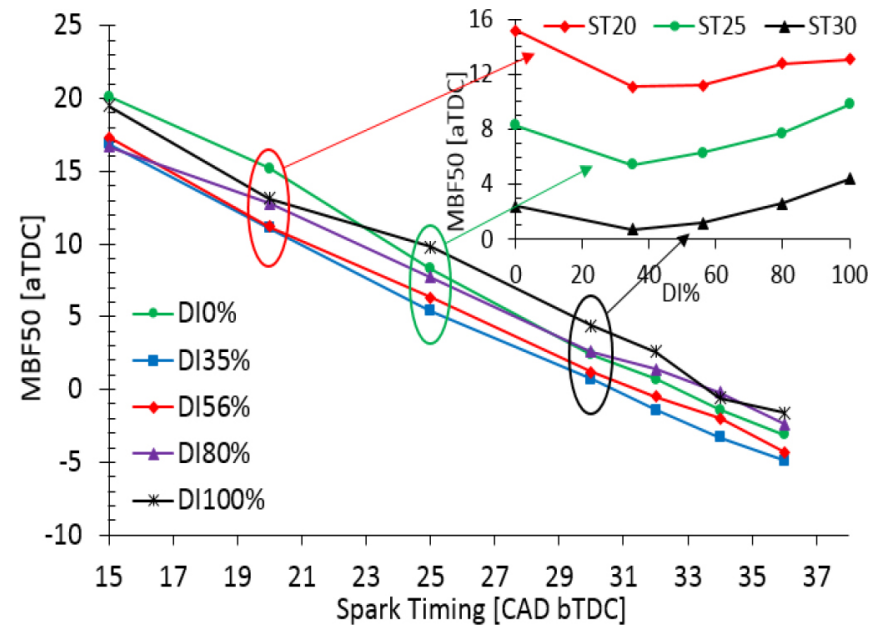

Figure 7. Effect of spark timing on MBF50 at different DI ratios and light load. 
Figure 5 shows the effect of the spark timing by comparing the cylinder pressure, HRR and MBF at ST15 and ST30 at light load and DI56\%. All the results were calculated from the cylinder pressure recorded experimentally. As shown in Figure 5, the $\mathrm{P}_{\max }$ rises significantly and the $\Theta_{\text {Pmax }}$ advances toward TDC by about 5 CAD when the spark timing is advanced from ST15 to ST30.

Correspondingly, the combustion performance, represented by the HRR and the MBF, improves considerably. At ST30, the peak HRR increases by about $4 \%$ and the major combustion duration (CA10$90 \%$ ) is $41.8 \%$ less when the spark timing is advanced from ST15 to ST30, as shown in Figure 6. Although the CA10-90\% at ST32 is slightly shorter than that at ST30 as shown Figure 6, the IMEP is maximum at ST30 which is the MBT timing [27]. The improved combustion performance can be attributed to the enhanced mixture quality and the reduced heat loss when the spark timing is advanced. Moreover, the relatively smaller combustion chamber volume where the MBF50 occurs can result in higher combustion pressure and temperature [37]. This may improve the combustion quality and increase the heat released rate and then reduce the combustion duration. However, greater combustion pressure and temperature may increase the engine heat loss from the combustion chamber walls caused by the high-temperature difference between the inside and outside the cylinder wall [요. These results partly explain why the IMEP and thermal efficiency decrease with further advance of spark timing from the MBT spark timing as shown in Figure 2 and Figure 3 . The greater heat losses can be associated with negative work caused by the extreme advance to the spark timing.

Figure 7 shows the effect of spark timing on MBF50 at different DI ratios at light load. As shown in Figure 7, the MBF50 consistently advances toward TDC due to the combined effect of advancing spark timing and DualEI strategy. For instance, at DI56\%, the MBF50 advances by 10 CAD when the spark timing is advanced from ST20 to ST30. On the other hand, the DualEI strategy also affects the phase of the combustion. Figure 7 also shows that MBF50 advances toward TDC with the increase of DI ratio at the same spark timing. At ST25, the MBF50 moves toward TDC by 3.0 CAD at DI35\% compared with DI0\%. However, further increase the DI ratio from DI $35 \%$ leads to MBF50 retarding from the TDC.

\section{Effect of Spark Timing on Engine Emissions}

Figure 8 and Figure 9 show the effect of spark timing on the ISCO and ISHC emissions at different DI ratios and light load. The ISCO and ISHC emissions increase with advanced spark timing and increased DI ratio. They were the results of incomplete combustion which could be caused by the insufficient time for the ethanol fuel to evaporate and mix homogeneously with air when the spark timing is advanced. Fuel impingement due to direct injection could be another cause and would result in local regions over-cooling and over-rich [39]. However, this is not a problem when ethanol fuel is port injected. As shown in Figure 8 and Figure 9 , the ISCO and ISHC are significantly reduced when the DI ratio is reduced from DI $35 \%$ to DI0\%. When the DI ratio is reduced, more fuel can be well evaporated in the port before it is mixed with air. This should reduce the fuel impingement and improve the mixture quality and thus the combustion performance [9].
Figure 8 shows that the ISCO emission increases with the advanced spark timing at different DI ratios. However, the effect of spark timing on ISCO is not obvious at DI0\% but becomes more and more significant when the DI ratio increases. At DI56\%, the ISCO emission increases by up to $71.84 \%$ when the spark timing is advanced from ST15 to ST42. This apparently resulted of incomplete combustion caused by the reduced time for fuel evaporation, mixture formation and then combustion when the spark timing is advanced. Regarding the effect of DI ratio, in general, the ISCO increases with the increased DI ratio. As shown in Figure 8, at ST30, the ISCO increases by up to $302.84 \%$ when the ratio of the DI increases from DI0 $\%$ to DI $100 \%$. The causes may include the over cooling effect and the high fuel impingement enhanced by the increased DI ratio.

Figure 9 shows that the ISHC emission increases by $109.64 \%$ at DI $35 \%$ and by $134 \%$ at DI $100 \%$ when the spark timing is advanced from ST15 to ST42. As reported in [25], the high DI ratio and the slow vaporisation of the ethanol fuel at low temperature could result in an ethanol film formed on the combustion chamber walls which resulted in over cooling when the fuel was evaporated. The combination of the over cooling effect and the high fuel impingement can deteriorate the mixture quality and thus the combustion performance in the range of DI ratio of DI56\%-DI $100 \%$.

Figure 10 shows the effect of the spark timing on the ISNOx emission at different DI ratios. Fundamentally, the ISNOx is strongly related to the combustion temperature and mixture quality $[\underline{6}, \underline{27}]$. As shown in Figure 10, the ISNOx increases with advanced spark timing from ST15 to ST42 possibly due to the increase of the combustion pressure and temperature when the spark timing is advanced. These results are consistent with that presented in Figure 5, the value of the combustion pressure and HRR increase with advanced spark timing leading to high combustion temperature and thus increased ISNOx. On the other hand, the ISNOx decreases with the increase of DI ratio. As shown in Figure 10, at ST30, the ISNOx emission decreases by $37.53 \%$ when DI ratio increases from DI0\% to DI56\% and $67.39 \%$ when DI ratio increases from DI0\% to DI $100 \%$. This is apparently attributed to the DI strategy and ethanol's great latent heat which reduce the combustion temperature [15], and consequently the ISNOx.

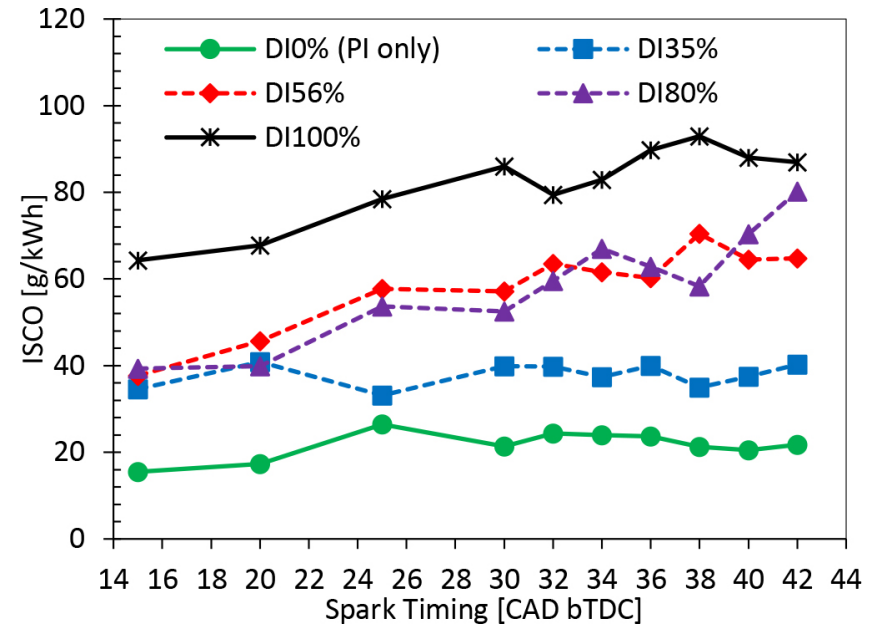

Figure 8. Effect of spark timing on ISCO at different DI ratios. 


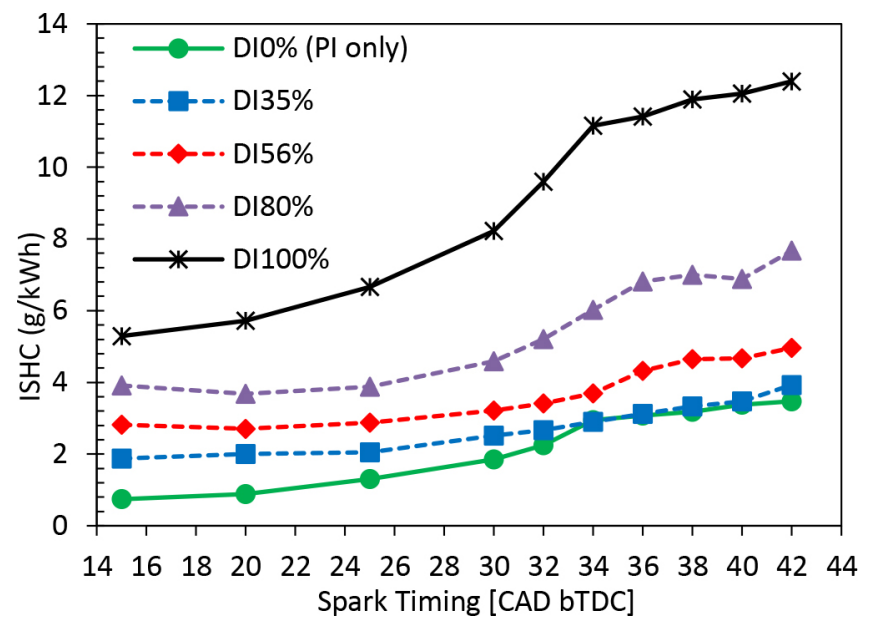

Figure 9. Effect of spark timing on ISHC Variation at different DI ratios.

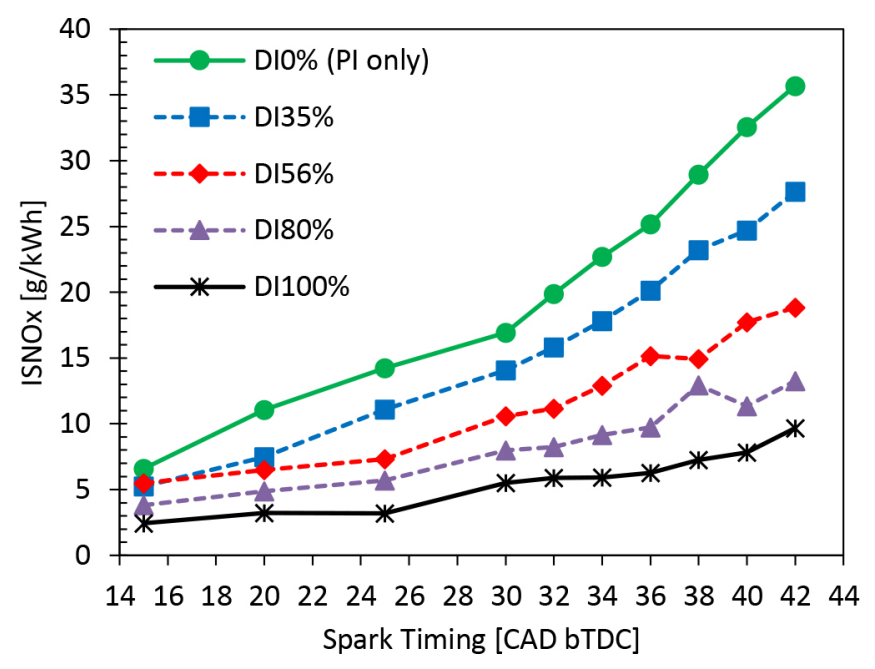

Figure 10. ISNOx Variation with spark timing at different DI ratios.

\section{Conclusions}

Experiments were performed to investigate the effect of spark timing on the performance of a naturally aspirated SI engine equipped with a DualEI system. The fuel volumetric ratio of the direct injection to the port injection was varied from $0 \%$ to $100 \%$. At each ratio, the spark timing was advanced from ST15 to ST42 at light load and from ST15 to ST32 at medium load. The effect of the spark timing on the IMEP, thermal efficiency and emissions were presented and discussed. Combustion characteristics were examined to understand the effect of spark timing. The results of this study are concluded as follows.

At light and medium loads, the IMEP and indicated thermal efficiency increased with the advanced spark timing. This effect on the indicated thermal efficiency was stronger at the light load than that at the medium load. MBT was identified in terms of the best IMEP and thermal efficiency. The MBT spark timing was $30 \mathrm{CAD}$ bTDC at light load and 23 CAD bTDC at medium load. At the MBT timing, the IMEP and engine thermal efficiency increased with the increased DI ratio.

At the MBT spark timing, $\Theta_{\text {Pmax }}$ was located at about 10 CAD aTDC at light load and about $12 \mathrm{CAD}$ aTDC at medium load. The CA10-90\% reduced when the DI ratio was increased when the spark timing was advanced from ST15 to ST30 at light load. Similarly, the MBF50 was advanced toward the TDC when the DI ratio was increased and the spark timing was advanced. However, further increase of the DI ratio from DI $35 \%$ to DI $100 \%$ increased the CA 10 $90 \%$ and retarded the MBF50 from TDC due to the fuel impingement and over cooling effect.

All the emissions were increased with advanced spark timing. However, the DualEI strategy had different effects on different emissions. The ISHC and ISCO were increased when the ratio of the DI was increased. This might be a result of incomplete combustion due to fuel impingement, mixture quality deterioration and over cooling effect [14]. ISNOx was reduced with the increased DI ratio because of the charge cooling effect enhanced by direct injection and consequently the reduced combustion temperature.

\section{References}

1. Bajpai, P., "Advances in Bioethanol," 2013 ed., Springer New Delhi Heidelberg New York Dordrecht London, India, 2013.

2. $\quad$ Eur-lex.europa.eu., "EUR-Lex," in, 2012.

3. Szulczyk, K.R., McCarl, B.A., Cornforth, G., "Market penetration of ethanol," Renewable and Sustainable Energy Reviews, 14(1): (394-403). 2010.

4. Bielaczyc, P., Szczotka, A., and Woodburn, J., "The Effect of Various Petrol-Ethanol Blends on Exhaust Emissions and Fuel Consumption of an Unmodified Light-Duty SI Vehicle," SAE Technical Paper 2011-24-0177, 2011, doi:10.4271/2011-24-0177.

5. Ramadhas, A.S., et al., "Effect of Ethanol-Gasoline Blends on Combustion and Emissions of a Passenger Car Engine at Part Load Operations," SAE International SAE Technical Paper 2016-28-0152, 2016.

6. Masum, B.M., et al., "Effect of ethanol-gasoline blend on NOx emission in SI engine," Renewable and Sustainable Energy Reviews, 24((209-222). 2013.

7. Jo, Y., Bromberg, L., and Heywood, J., "Optimal Use of Ethanol in Dual Fuel Applications: Effects of Engine Downsizing, Spark Retard, and Compression Ratio on Fuel Economy," SAE Int. J. Engines 9(2):1087-1101, 2016, doi:10.4271/2016-01-0786.

8. Smith, P., Heywood, J., and Cheng, W., "Effects of Compression Ratio on Spark-Ignited Engine Efficiency," SAE Technical Paper 2014-01-2599, 2014, doi:10.4271/2014-01-2599.

9. Huang, Y., Hong, G., Huang, R., "Investigation to charge cooling effect and combustion characteristics of ethanol direct injection in a gasoline port injection engine," Applied Energy, 160((244-254). 2015.

10. Liu, H., et al., "Dual-Fuel Spark Ignition (DFSI) combustion fuelled with different alcohols and gasoline for fuel efficiency," Fuel, 157((255-260). 2015.

11. Yang, B., et al., "Experimental and numerical study on different dual-fuel combustion modes fuelled with gasoline and diesel," Applied Energy, 113((722-733). 2014.

12. Catapano, F., Di Iorio, S., Sementa, P., and Vaglieco, B., "Investigation of Ethanol-Gasoline Dual Fuel Combustion on the Performance and Exhaust Emissions of a Small SI Engine," SAE Technical Paper 2014-01-2620, 2014, doi:10.4271/201401-2620. 
13. Zhuang, Y., Hong, G., "Primary investigation to leveraging effect of using ethanol fuel on reducing gasoline fuel consumption," Fuel, 105((425-431). 2013.

14. Zhu, G., Hung, D., Schock, H., "Combustion characteristics of a single-cylinder spark ignition gasoline and ethanol dualfuelled engine," Proceedings of the Institution of Mechanical Engineers, Part D: Journal of Automobile Engineering, 224(3): (387-403). 2010.

15. Kasseris, E. and Heywood, J., "Charge Cooling Effects on Knock Limits in SI DI Engines Using Gasoline/Ethanol Blends: Part 1-Quantifying Charge Cooling," SAE Technical Paper 2012-01-1275, 2012, doi:10.4271/2012-01-1275.

16. Kasseris, E. and Heywood, J., "Charge Cooling Effects on Knock Limits in SI DI Engines Using Gasoline/Ethanol Blends: Part 2-Effective Octane Numbers," SAE Int. J. Fuels Lubr. 5(2):844-854, 2012, doi:10.4271/2012-01-1284.

17. Boretti, A., "Analysis of Design of Pure Ethanol Engines," SAE Technical Paper 2010-01-1453, 2010, doi:10.4271/2010-01-1453.

18. Costa, R.C., Sodré, J.R., "Hydrous ethanol vs. gasoline-ethanol blend: Engine performance and emissions," Fuel, 89(2): (287293). 2010.

19. Stein, R., House, C., and Leone, T., "Optimal Use of E85 in a Turbocharged Direct Injection Engine," SAE Int. J. Fuels Lubr. 2(1):670-682, 2009, doi:10.4271/2009-01-1490.

20. Koç, M., et al., "The effects of ethanol-unleaded gasoline blends on engine performance and exhaust emissions in a sparkignition engine," Renewable Energy, 34(10): (2101-2106). 2009.

21. Sjöberg, M., Zeng, W., Singleton, D., Sanders, J. et al., "Combined Effects of Multi-Pulse Transient Plasma Ignition and Intake Heating on Lean Limits of Well-Mixed E85 DISI Engine Operation," SAE Int. J. Engines 7(4):1781-1801, 2014, doi: 10.4271/2014-01-2615.

22. Aleiferis, P., et al., "Mechanisms of spray formation and combustion from a multi-hole injector with E85 and gasoline," Combustion and Flame, 157(4): (735-756). 2010.

23. Zhuang, Y., Hong, G., "Effects of direct injection timing of ethanol fuel on engine knock and lean burn in a port injection gasoline engine," Fuel, 135(0): (27-37). 2014.

24. Balki, M.K., Sayin, C., "The effect of compression ratio on the performance, emissions and combustion of an SI (spark ignition) engine fueled with pure ethanol, methanol and unleaded gasoline," Energy, 71((194-201). 2014.

25. Huang, Y., Hong, G., Huang, R., "Numerical investigation to the dual-fuel spray combustion process in an ethanol direct injection plus gasoline port injection (EDI+GPI) engine," Energy Conversion and Management, 92(0): (275-286). 2015.

26. Nizar F. O. Al-Muhsen, J.J.W., Hong Guang, "Investigation to Combustion and Emission Characteristics of the Dual Ethanol Injection Spark Ignition Engine," 20th Australasian Fluid Mechanics Conference, Perth, Australia, 2016.

27. Heywood, J.B., "Internal Combustion Engine Fundamentals," McGraw-Hill, Inc., 1988.
28. Ayala, F., Gerty, M., and Heywood, J., "Effects of Combustion Phasing, Relative Air-fuel Ratio, Compression Ratio, and Load on SI Engine Efficiency," SAE Technical Paper 2006-01-0229, 2006, doi:10.4271/2006-01-0229.

29. Yaws, C.L., "Yaws' Handbook of Thermodynamic Properties for Hydrocarbons and Chemicals," Knovel.

30. Tian, G., et al., "Laminar burning velocities of 2, 5-dimethylfuran compared with ethanol and gasoline," Energy \& Fuels, 24(7): (3898-3905). 2010.

31. Huang, Y., Huang, S., Deng, P., Huang, R. et al., "The Effect of Fuel Temperature on the Ethanol Direct Injection Spray Characteristics of a Multi-hole Injector," SAE Int. J. Fuels Lubr. 7(3):792-802, 2014, doi:10.4271/2014-01-2734.

32. Huang, Y., et al., "Spray and evaporation characteristics of ethanol and gasoline direct injection in non-evaporating, transition and flash-boiling conditions," Energy Conversion and Management, 108((68-77). 2016.

33. Zhuang, Y. and Hong, G., "Investigation to Leveraging Effect of Ethanol Direct Injection (EDI) in a Gasoline Port Injection (GPI) Engine," SAE Technical Paper 2013-01-1322, 2013, doi:10.4271/2013-01-1322.

34. Turner, D., et al., "Combustion performance of bio-ethanol at various blend ratios in a gasoline direct injection engine," Fuel, 90(5): (1999-2006). 2011.

35. Engler-Pinto, C. and de Nadai, L., "Volumetric Efficiency and Air-Fuel Ratio Analysis For Flex Fuel Engines," SAE Technical Paper 2008-36-0223, 2008, doi:10.4271/2008-36-0223.

36. Reitz, R.D., "Directions in internal combustion engine research," Combustion and Flame, 160(1): (1-8). 2013.

37. Sayin, C., Canakci, M., "Effects of injection timing on the engine performance and exhaust emissions of a dual-fuel diesel engine," Energy Conversion and Management, 50(1): (203-213). 2009.

38. Pulkrabek, W.W., "Engineering Fundamentals of the Internal Combustion Engines," Prentice-Hall, Inc., United States of America, 1997.

39. Huang, Y., Hong, G., "Investigation of the effect of heated ethanol fuel on combustion and emissions of an ethanol direct injection plus gasoline port injection (EDI + GPI) engine," Energy Conversion and Management, 123((338-347). 2016.

\section{Contact Information}

Nizar Faisal Odah Al-Muhsen

School of Mechanical and Mechatronic Engineering

University of Technology Sydney

Nizar.Al-Muhsen@student.uts.edu.au

Guang HONG

School of Mechanical and Mechatronic Engineering

University of Technology Sydney

guang.hong@uts.edu.au 


\section{Acknowledgments}

The scholarship provided by the Iraqi Ministry of Higher Education $\&$ Scientific Research is gratefully appreciated.

\section{Definitions/Abbreviations}

aTDC - After top dead centre

bTDC - Before top dead centre

CAD - Crank angle degree

CA10-90\% - The major combustion duration

DI - Direct fuel injection

DualEI - Dual ethanol injection

EDI - Ethanol direct injection

EPI - Ethanol port injection

GDI - Gasoline direct injection

GPI - Gasoline port injection

HC - Hydrocarbon

HRR - Heat release rate

IC Engine - Internal combustion engine
IMEP - Indicated mean effective pressure

ISCO2 - Indicated specific carbon dioxide

ISCO - Indicated specific carbon monoxide

ISHC - Indicated specific Hydrocarbon

ISNOx - Indicated specific nitric oxide

MBF - Mass burnt fraction

MBT - Minimum spark advance for best torque

MBF50 - Combustion phase when 50\% of the fuel is burnt.

P-cylinder - Cylinder Pressure

PI only - Port fuel injection only

$\mathbf{P}_{\text {max }}$ - Maximum cylinder pressure

RPM - Revolution per minute

ST - Spark timing

TDC - Top dead centre

$\lambda$ - Equivalent ratio

$\boldsymbol{\Theta}_{\text {Pmax }}$ - Maximum pressure phase

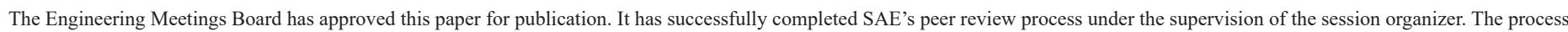
requires a minimum of three (3) reviews by industry experts.

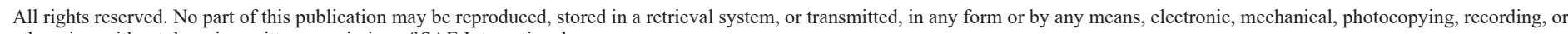
otherwise, without the prior written permission of SAE International.

Positions and opinions advanced in this paper are those of the author(s) and not necessarily those of SAE International. The author is solely responsible for the content of the paper.

ISSN 0148-7191

http://papers.sae.org/2017-01-2230 